\title{
STUDIES OF CUTICULAR DIFFUSION OF XENOBIOTICS USING LASER SCANNING CONFOCAL MICROSCOPY
}

\author{
Z.Q. LIU, J.A. ZABKIEWICZ and R.E. GASKIN
}

New Zealand Forest Research Institute Ltd, Private Bag 3020, Rotorua, New Zealand

Radiolabelled compounds are generally used to quantitate the uptake of pesticides into plant foliage. To study the localisation of these compounds inside plant tissues or cells, more complex techniques, such as microautoradiography are necessary. Fluorescence microscopy can also be used to visualise specific probes inside plant tissues and cells. However, delicate tissue sectioning is involved and it is difficult to achieve high resolution due to out-of-focus flare. Laser scanning confocal microscopy has several advantages in this field. It is non-destructive, fast for sample preparation and most of all, provides high lateral and axial resolution. Also three dimensional (3D) volume investigation and real time imaging (4D) are possible. A method has been developed to study the trans-cuticular diffusion of xenobiotics into plant leaves. Fluorescein has proved to be a suitable probe for this purpose. It is non-toxic, water soluble and has a low molecular weight similar to that of most pesticides. Most importantly, its emission spectrum can be easily separated from chlorophyll autofluorescence. Using this technique, the diffusion pathway of fluorescein into leaves of different plant species and its sub-cellular compartmentation, and the influence of surfactants on this process, have been established.

\section{DUST AND 1080 RESIDUE CONTAMINATION AFTER AERIAL SOWING OF 1080 BAITS FOR POSSUM CONTROL}

\author{
L.H. BOOTH, G.R.G. WRIGHT, L.E. BROWN, C.D RADFORD and C.T. EASON \\ Landcare Research, P.O. Box 69, Lincoln, Canterbury
}

The risk of environmental contamination by 1080 dust during possum control operations was assessed after three such operations. This research has been prompted by the lack of data on the potential risk of 1080 poisoning of invertebrates in leaf litter. Cereal baits containing $0.15 \% 1080$ were aerially applied and samples of dust, plants, leaf litter, soil and water were collected prior to and up to 30 days after bait application. A maximum concentration of $25.2 \mu \mathrm{g} 1080 / \mathrm{m}^{2}$ was detected in dust within the control zone immediately after aerial application of 1080 baits. Lower concentrations of 1080 were found outside the treatment areas indicating relatively little dust drift. There was detectable 1080 found in plant, leaf-litter and soil samples after two of the three operations. However, the residues were very low indicating only minor contamination by 1080 . Using the maximum concentration of 1080 found in leaf litter and $\mathrm{LD}_{50}$ values from the literature for invertebrates, these results indicate that 1080 does not pose a significant risk of poisoning to resident leaf-litter invertebrates. 